\title{
SÍNDROME DE GORLIN \\ (SÍNDROME NEVOIDE BASOCELULAR)
}

\section{GORLIN SYNDROME \\ (NEVOID BASAL CELL CARCINOMA SYNDROME)}

\author{
DE-DOMINGO B ${ }^{1}$, GONZÁLEZ F ${ }^{2}$, LORENZO P 3
}

\section{RESUMEN}

Caso clínico: Varón de 77 años con enfermedad de Parkinson y demencia senil. Presentaba múltiples carcinomas basocelulares faciales y ectropión en ojo izquierdo. Comenzó con insuficiencia respiratoria y fue diagnosticado de ameloblastoma en fosa nasal izquierda e intervenido quirúrgicamente.

Discusión: El síndrome de Gorlin es una enfermedad autosómica dominante caracterizada por carcinomas basocelulares, anomalías esqueléticas y del sistema nervioso. Su pronóstico depende de la evolución de las lesiones malignas.

Es importante sospechar un síndrome de Gorlin en pacientes jóvenes con múltiples carcinomas basocelulares o en pacientes que acuden al oftalmólogo con estas lesiones a nivel palpebral, ya que su seguimiento es fundamental.

Palabras clave: Síndrome de Gorlin, síndrome basocelular nevoide, carcinoma basocelular, ameloblastoma, gen PTCH.

\section{INTRODUCCIÓN}

El Síndrome de Gorlin una enfermedad autosómica dominante, que afecta de manera similar a hombres y mujeres. Estos pacientes desarrollan múltiples carcinomas basocelulares, incluso en zonas no expuestas al

\section{ABSTRACT}

Clinical case: A 77 year-old male patient with Parkinson's disease and senile dementia had many facial basal cell carcinomas and an ectropion of the left eye. When he experienced respiratory difficulty he was diagnosed to have an ameloblastoma in left nostril requiring surgery.

Discussion: Gorlin syndrome is an autosomal dominant condition characterized by basal cell carcinomas, and skeletal and neurological anomalies. The presence of multiple basal cell carcinomas on the eyelids in a child or in a young patient should alert ophthalmologists to the possibility of this syndrome (Arch Soc Esp Oftalmol 2008; 83: 321-324).

Key words: Gorlin syndrome, nevoid basal cell carcinoma syndrome, basal cell carcinoma, ameloblastoma, PTCH gene.

\footnotetext{
Recibido: 18/5/07. Aceptado: 9/4/08.

Hospital Universitario de Santiago de Compostela. Santiago de Compostela. España.

1 Licenciado en Medicina. Servicio de Oftalmología.

2 Doctor en Medicina. Servicio de Oftalmología.

${ }^{3}$ Licenciado en Medicina. Servicio de Anatomía Patológica.
}

Correspondencia:

Begoña de Domingo Barón

Moas de Abaixo, 4C

15897 Santiago de Compostela (La Coruña)

España

E-mail: bdedbar@yahoo.es

sol. Dado que también cursa con anomalías esqueléticas y del sistema nervioso, se conoce como «quinta facomatosis». Este síndrome es relevante en oftalmología porque las lesiones cutáneas frecuentemente afectan a los párpados. A continuación se describe el caso de un paciente con este síndrome. 


\section{CASO CLÍNICO}

Paciente varón de 77 años diagnosticado de síndrome de Gorlin, que desde hacía más de veinte años presentaba carcinomas basocelulares en el área facial. En 1995 acudió a consulta de otorrrinolaringología por insuficiencia respiratoria, siendo diagnosticado de ameloblastoma de seno maxilar izquierdo e intervenido quirúrgicamente (fig. 1). En 2004 presentó una recidiva de este proceso, pero dado el estado neurológico del paciente (demencia subcortical de componente vascular y enfermedad de Parkinson) se decidió no reintervenir. Ese mismo año es remitido al servicio de oftalmología por presentar un ectropion y una lesión tumoral de 2 milímetros en el borde libre del párpado inferior del ojo izquierdo (fig. 2). Bajo anestesia local se corrige el ectropion relizando una suspensión del párpado inferior con bandeleta tarsal y exéresis de la lesión del borde libre. El informe de anatomía patológica describe la lesión como carcinoma basocelular que respeta los márgenes quirúrgicos, por lo que no se realiza tratamiento adicional. Actualmente la situación clínica del paciente está estabilizada.

\section{DISCUSIÓN}

Las publicaciones realizadas sobre el síndrome de Gorlin ponen de manifiesto la existencia de una alteración genética vinculada a anomalías esquelé-

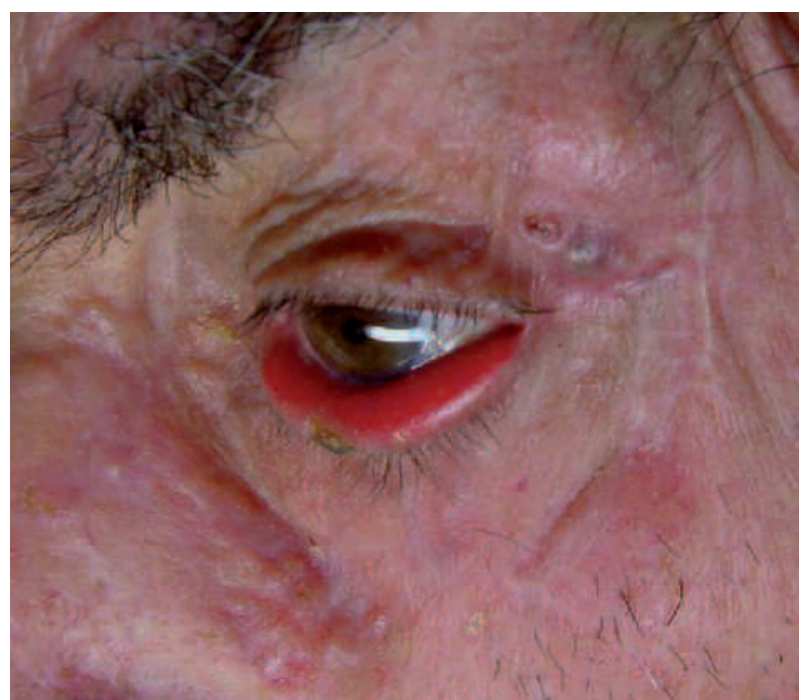

Fig. 1: Ectropión y lesión tumoral en borde libre de párpado inferior de ojo izquierdo.

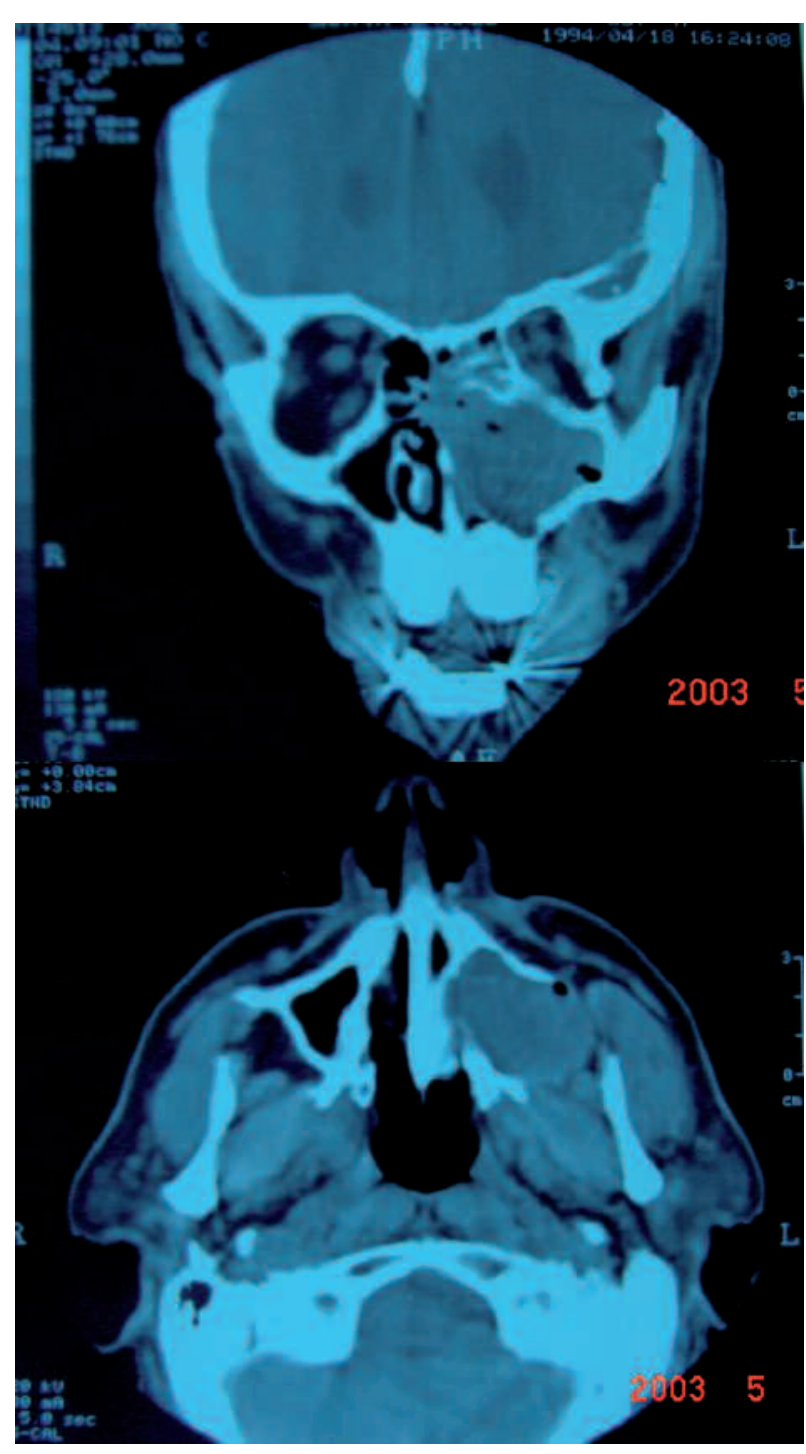

Fig. 2: TAC (cortes axiales y coronales): ameloblastoma del seno maxilar izquierdo.

ticas y del desarrollo, en el que aparecen carcinomas de células basales. Pueden aparecer tumoraciones como queratoquistes maxilares, meduloblastomas, ameloblastomas, fibromas ováricos. Se debe a la alteración del gen PTCH, localizado en el cromosoma 9q22.3-q31 (1). La biología molecular de los tumores que aparecen en este síndrome es similar a la del retinoblastoma, caracterizada por una mutación en un oncogen recesivo. El gen PTCH actúa tanto en el desarrollo del individuo como en la supresión tumoral. Las anomalías congénitas son consecuencia de la mutación en una de las copias de este gen, mientras que la aparición de tumoraciones 
2 o más carcinomas basocelulares en $<20$ años

Queratoquistes maxilares confirmados con estudio histopatológico

3 o más pits palmo-plantares

Calcificación bilamelar de la hoz cerebral

Costillas bífidas, fusionadas o marcadamente expandidas Pariente de primer grado con síndrome de Gorlin
Macrocefalia

Malformaciones congénitas: fisura labial o palatina, prominencia frontal, facies anchas, hipertelorismo moderado a severo Otras alteraciones esqueléticas: deformación de Sprengel, marcada deformación pectoral, marcada sindactilia

Anomalías radiográficas: puente en silla turca, anomalías vertebrales (hemivértebras, fusión o elongación de los cuerpos vertebrales), defectos de modelaje de manos y pies, o radiolucideces en forma de llamas en las manos o pies

Fibroma ovárico

Meduloblastoma requiere la mutación de las dos copias. Nuestro paciente presentaba un ameloblastoma maxilar recidivante, tumoración frecuente en este síndrome (11\%), siendo más prevalente la existencia de queratoquistes múltiples (24\%).

La incidencia del síndrome de Gorlin es de 1 por cada 50.000-150.000 habitantes, siendo más elevada en ciertas regiones de Australia, donde la exposición solar intensa es mayor. La forma de presentación más habitual es la aparición de quistes dentales o carcinomas basocelulares en la tercera década de la vida. Es importante sospechar este síndrome en pacientes con carcinomas basocelulares en edad pediátrica. El diagnóstico es fundamentalmente clínico, para lo que hay que tener en cuenta los criterios de Kimonis (1997) que consideran necesaria la presencia de 2 criterios mayores o de 1 mayor y 2

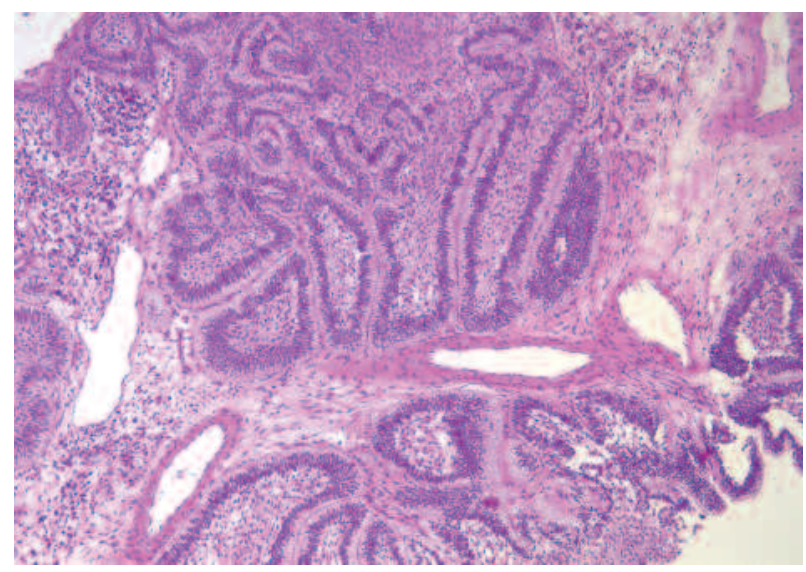

Fig. 3: Ameloblastoma: proliferación neoplásica constituida por células cilíndricas altas con polarización del núcleo en la superficie opuesta a la membrana basal. La porción central de dichos islotes está compuesta por una trama laxa de células que recuerdan el retículo estrellado. menores (tabla I) $(2,3)$. En nuestro paciente, al igual que en la mayoría de casos, los múltiples carcinomas basocelulares presentes en distintas regiones y el ameloblastoma maxilar fueron suficientes para su diagnóstico, no siendo necesaria la realización de determinaciones genéticas para confirmarlo.

Desde el punto de vista oftalmológico, además de los carcinomas basocelulares de párpados, presentes en los anejos de nuestro paciente de forma múltiple, se han descrito disgenesias en el segmento anterior con cataratas y anomalía de Peter, mielinización de fibras nerviosas y vítreo primario persistente, y recientemente alteraciones vitreoretinianas con formación de membranas epiretinianas (4). El hipertelorismo aumenta la separación de las órbitas y tiene valor diagnóstico en este síndrome (2).

El tratamiento de este síndrome es multidisciplinario, dependiendo de los sistemas que se encuentren afectados. En nuestro caso fue precisa la colaboración de los servicios de dermatología, cirugía maxilofacial, otorrinolaringología, neurología, oftalmología y anatomía patológica para su diagnóstico y tratamientos posteriores. El pronóstico va a depender de la evolución de las lesiones malignas así como de los problemas asociados o secundarios.

Los queratoquistes representan el $10 \%$ de los quistes de los maxilares. Pueden aparecer de forma esporádica o asociados al síndrome de Gorlin. Se ha observado que las alteraciones en el gen PTCH están asociadas tanto a los queratoquistes aislados como a los asociados con el síndrome de Gorlin (5).

La aparición de un ameloblastoma es infrecuente. Nuestro paciente presentó un ameloblastoma maxilar izquierdo, que a pesar de intervenirlo quirúrgicamente volvió a recidivar. Clínicamente, se presentan como un aumento de volumen que compromete una tabla ósea, en cambio, el ameloblasto- 
ma suele producir gran expansión de las corticales. Es fundamental la realización de un TAC para delimitar la extensión de estas lesiones radiorresistentes, para su posterior resección, como realizamos en nuestro caso.

\section{BIBLIOGRAFÍA}

1. Ragge NK, Salt A, O Collin JR, Michalski A, Farndon PA. Gorlin syndrome: the PTCH gene links ocular developmental defects and tumour formation. Br J Ophthalmol 2005; 89: 988-991.
2. Anh SG, Lim YS, Kim DK, Lee SH, Yoon JH. Nevoid basal cell carcinoma syndrome: a retrospective analysis of 33 affected korean individuals. Int J Oral Maxillofac Surg 2004; 33: 458-462.

3. Lo Muzio L, Nocini P, Bucci P, Pannone G, Consolo U, Procaccini M. Early diagnosis of nevoid basal cell carcinoma syndrome. J Am Dent Assoc 1999; 130: 669-674.

4. Honavar SG, Shields JA, Shields CL, Eagle RC Jr, Demirci H, Mahmood EZ. Basal cell carcinoma of the eyelid associated with Gorlin-Goltz syndrome. Ophthalmology 2001; 108: 1115-1123.

5. Scott A, Strouthidis NG, Robson AG, Forsyth J, Maher ER, Schlottmann PG, et al. Bilateral epiretinal membranes in Gorlin syndrome associated with a novel PTCH mutation. Am J Ophthalmol 2007; 143: 346-348. 